\title{
Identification of pharmacological chaperones as potential therapeutic agents to treat phenylketonuria
}

\author{
Angel L. Pey, ${ }^{1}$ Ming Ying, ${ }^{1}$ Nunilo Cremades, ${ }^{2,3}$ Adrian Velazquez-Campoy, ${ }^{3}$ \\ Tanja Scherer, ${ }^{4}$ Beat Thöny, ${ }^{4}$ Javier Sancho, ${ }^{2,3}$ and Aurora Martinez ${ }^{1}$

\begin{abstract}
1Department of Biomedicine, University of Bergen, Bergen, Norway. ${ }^{2}$ Department of Biochemistry and Molecular and Cellular Biology, Universidad de Zaragoza, Zaragoza, Spain. ${ }^{3}$ Biocomputation and Complex Systems Physics Institute (BIFI), Zaragoza, Spain. ${ }^{4}$ Division of Clinical Chemistry and Biochemistry, Department of Pediatrics, University of Zurich, Zurich, Switzerland.
\end{abstract}

\begin{abstract}
Phenylketonuria (PKU) is an inborn error of metabolism caused by mutations in phenylalanine hydroxylase $(P A H)$. Over 500 disease-causing mutations have been identified in humans, most of which result in PAH protein misfolding and increased turnover in vivo. The use of pharmacological chaperones to stabilize or promote correct folding of mutant proteins represents a promising new direction in the treatment of misfolding diseases. We performed a high-throughput ligand screen of over 1,000 pharmacological agents and identified 4 compounds (I-IV) that enhanced the thermal stability of PAH and did not show substantial inhibition of PAH activity. In further studies, compounds III (3-amino-2-benzyl-7-nitro-4-(2-quinolyl)-1,2-dihydroisoquinolin-1-one) and IV (5,6-dimethyl-3-(4-methyl-2-pyridinyl)-2-thioxo-2,3-dihydrothieno[2,3-d]pyrimidin-4(1H)-one) stabilized the functional tetrameric conformation of recombinant WT-PAH and PKU mutants. These compounds also significantly increased activity and steady-state PAH protein levels in cells transiently transfected with either WT-PAH or PKU mutants. Furthermore, PAH activity in mouse liver increased after a 12-day oral administration of low doses of compounds III and IV. Thus, we have identified 2 small molecules that may represent promising alternatives in the treatment of PKU.
\end{abstract}

\section{Introduction}

Phenylalanine hydroxylase (PAH) is a nonheme iron-dependent enzyme that catalyzes the hydroxylation of L-Phe to L-Tyr in the presence of $(6 R)$-L-erythro-5,6,7,8-tetrahydrobiopterin $\left(\mathrm{BH}_{4}\right)$ and molecular dioxygen as cosubstrates. In humans, liver PAH activity provides L-Tyr for protein and neurotransmitter biosynthesis, it is involved in energy metabolism, and importantly, it prevents plasma L-Phe accumulation, which is toxic to the brain. Defective $\mathrm{PAH}$ activity is associated with phenylketonuria (PKU), an inherited metabolic disease characterized by hyperphenylalaninemia and responsible for mental retardation if untreated (1). About 500 disease-causing $P A H$ mutations have been described (extensively compiled in PAHdb at http://www.pahdb.mcgill.ca/) (2). Most missense mutations result in misfolding of $\mathrm{PAH}$ and increased protein turnover in vitro and probably in vivo, pointing to a decreased conformational stability as the major molecular mechanism for the lossof-PAH function in PKU (3). Restriction of L-Phe intake by using artificial dietary formulations and early diagnosis through new-

Nonstandard abbreviations used: ANS, 8-anilino 1-naphthalene sulfonic acid; $\mathrm{BH}_{4}$, (6R)-L-erythro-5,6,7,8-tetrahydrobiopterin; $C_{0.5}$, concentration for half-maximal binding; compound I, 5-amino-3-(5-methyl-3-phenyl-4-isoxazolyl)-1H-pyrazole-4-carbonitrile; compound II, 1-benzhydryl-4-(1-methyl-4-nitro-1H-imidazol-5-yl)piperazine; compound III, 3-amino-2-benzyl-7-nitro-4-(2-quinolyl)-1,2-dihydroisoquinolin-1-one; compound IV, 5,6-dimethyl-3-(4-methyl-2-pyridinyl)-2-thioxo-2,3-dihydrothieno[2,3d]pyrimidin-4(1H)-one; $\lambda_{\text {em }}$, emission wavelength; $\lambda_{\text {exc }}$, excitation wavelength; HTS, high-throughput screening; PAH, phenylalanine hydroxylase; PKU, phenylketonuria; RTS, Rapid Translation System; SEC, size-exclusion chromatography; $T_{0.5}$, half-denaturation temperature; $T_{50}$, half-inactivation temperature.

Conflict of interest: A.L. Pey, M. Ying, N. Cremades, A. Velazquez-Campoy, J. Sancho, and A. Martinez have a patent pending on the use of compounds I-IV in the treatment of PKU.

Citation for this article: J. Clin. Invest. 118:2858-2867 (2008). doi:10.1172/JCI34355 born screening tests has led to remarkable success in preventing the major manifestations of the disease, including mental retardation (4). However, lifetime dietary therapy is expensive as well as a social burden, and the NIH consensus panel has encouraged research for alternative therapies for PKU (5). Currently, different strategies to partially or totally substitute a low-Phe diet to treat PKU are available. $\mathrm{BH}_{4}$ supplementation has been demonstrated to reduce plasma L-Phe levels in the short and long term and increase L-Phe tolerance in mild and severe PKU phenotypes (6-8). The correction mechanisms are probably multifactorial, involving stimulation of activity by intracellular increase of the concentration of cofactor, correction of affinity defects, and stabilization of PAH mutant proteins against degradation/inactivation $(9,10)$. Large neutral amino acid supplementation is based on the reversal of $\mathrm{L}$-Phe-induced inhibition of the transport of mostly L-Tyr by the L-type amino acid carrier across the blood-brain barrier. Both these supplementations may allow less (but still) restrictive L-Phe diets (11). Two alternative approaches are currently being investigated to treat PKU, both envisioning complete substitution of the classic low-L-Phe diet, i.e., enzyme replacement therapy using formulations of PEG-modified phenylalanine ammonia lyase (12) and gene therapy $(13,14)$. Both approaches are still in their experimental infancy.

Many human genetic diseases are in fact misfolding diseases, caused by mutations that impair correct protein folding and - in some instances - trafficking (15). Based on the efficiency of the cellular protein quality control systems in degrading the aberrantly folded proteins, misfolding diseases are classified into 2 main groups, depending on the pathogenic mechanism (15): (a) (toxic) gain of function, in which the mutant protein is usually resistant to degradation and aggregates forming amyloid deposits; or (b) loss of function, in which the mutant is efficiently degraded and disease 


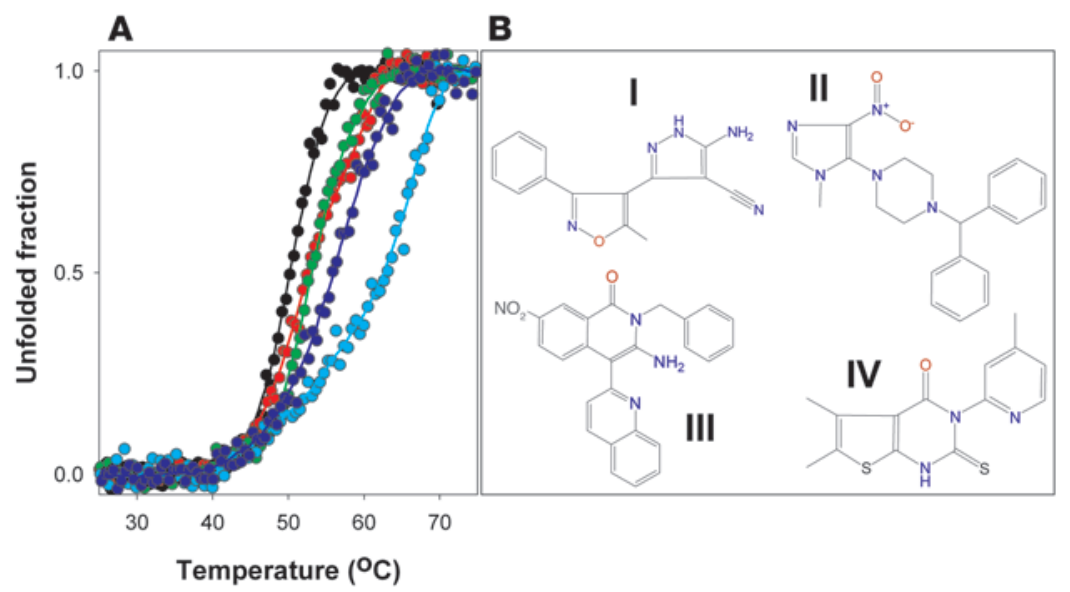

Figure 1

Four hit compounds found to stabilize $\mathrm{PAH}$ in the HTS and further detailed fluorescence analyses. (A) Representative thermal denaturation profiles of WT$\mathrm{PAH}$ in the absence (black) or presence of $100 \mu \mathrm{M}$ of the hit compounds I (red), II (green), III (light blue), and IV (dark blue), resulting from the HTS procedure as monitored by ANS fluorescence. (B) Chemical structures of compounds I, II, III, and IV. arises from a deficient metabolic/cellular function, as in PKU. A new therapeutic approach to treating misfolding diseases is the use of so-called pharmacological chaperones $(16,17)$ : structure-directed small molecules that specifically stabilize the native state of the target protein (18) and/or facilitate the folding of nonnative intermediate states toward the native protein $(19,20)$. Pharmacological chaperones are either developed by an optimization of natural or synthetic substrates or inhibitors, which aims at increasing binding affinity and bioavailability, or by screening procedures (18). Pharmacological chaperones are potentially useful to treat both loss-offunction and gain-of-function misfolding diseases (15) and have shown their potential in the treatment of several genetic disorders and notably lysosomal storage diseases (21).

Here we present an integrated methodological approach leading to the discovery of compounds with therapeutic potential as pharmacological chaperones to treat PKU, which is based on their stabilizing effect on WT-PAH and selected PKU mutant variants. A commercially available chemical library was screened using WT-PAH in a high-throughput thermal stability assay (22). Potential hit compounds were found, and 2 of those, namely 3 -amino-2-benzyl7-nitro-4-(2-quinolyl)-1,2-dihydroisoquinolin-1-one (compound III) and 5,6-dimethyl-3-(4-methyl-2-pyridinyl)-2-thioxo-2,3-dihydrothieno[2,3-d]pyrimidin-4(1H)-one (compound IV) were, in addition, effective in increasing the steady-state protein and activity levels of WT-PAH and PKU mutants in a cellular system. Oral administration of compounds III and IV to normal C57BL/ 6 mice at low doses increased PAH activity to levels comparable to $\mathrm{BH}_{4}$ loading experiments (23) and without apparent side effects. These compounds thus appear as potential pharmacological chaperones with suitable pharmacokinetic properties.

\section{Results}

High-throughput screening for pharmacological chaperones. Fluorescencebased high-throughput screening (HTS) searching for PAH stabilizing ligands was performed by monitoring ligand-binding effects on the thermal stability of WT-PAH as upward shifts of the half-denaturation temperature ( $T_{0.5}$ value) (22). Initial validation of the HTS thermal upshift method was performed by studying the stabilizing effect of the natural substrate (L-Phe) on PAH thermal stability in a concentration-dependent manner (not shown), which reproduced the stabilizing effect as seen in previous studies of PAH thermal denaturation (24). One thousand chemical compounds randomly selected from a commercially available compound library (May- bridge HitFinder Collection database) were screened; the complete chemical library comprises 16,000 chemically diverse lead compounds. Ligands that significantly stabilize PAH were identified by comparing $T_{0.5}$ values obtained in the absence or presence of compounds, and 14 of those were selected as potential hit compounds. Further experiments performed in a standard cell fluorimeter under conditions identical to those used for HTS confirmed a significant and reproducible stabilizing effect for 4 of these hit compounds (compounds I-IV) [compound I, (5-amino-3-(5-methyl-3-phenyl4-isoxazolyl)-1H-pyrazole-4-carbonitrile); compound II, (1-benzhydryl-4-(1-methyl-4-nitro-1H-imidazol-5-yl)piperazine)] (Figure 1). As expected, the stabilizing effect on WT-PAH (Table 1) was concentration dependent for compounds I-IV, being significant at $25 \mu \mathrm{M}$ for compounds III and IV (Figure 2). Binding of compounds I-IV to WT-PAH was also studied by quenching of Trp-emission fluorescence spectroscopy (Figure 2). Compounds I, III, and IV bound to WT-PAH with affinities in the low micromolar range (concentration for half-maximal binding $\left[C_{0.5}\right]$ at $\left.1-5 \mu \mathrm{M}\right)$, whereas compound II displayed lower affinity $\left(C_{0.5}=14 \mu \mathrm{M}\right.$; Table 1$)$.

Effects of stabilizing hit compounds on PAH enzyme kinetics. The effect of the hit compounds I-IV on the kinetic parameters of WT-PAH are summarized in Table 2 . The analyses indicate a weak inhibition of the enzyme by the compounds ( $<15 \%$ reduction of $\left.V_{\max }\right)$. Only compounds I and IV increased the $K_{\mathrm{m}}$ for $\mathrm{BH}_{4}(\sim 20 \%$ and $50 \%$, respectively) (Table 2), and $K_{i}$ values of approximately $500 \mu \mathrm{M}$ and

\section{Table 1}

Half-denaturation temperatures and thermal upshifts for WT-PAH in the absence or presence of hit compounds and concentration of the compounds for half-maximal binding

$\begin{array}{lccc}\text { Compound } & \boldsymbol{T}_{0.5^{\mathrm{A}}}\left({ }^{\circ} \mathbf{C}\right) & \Delta \boldsymbol{T}_{0.5}\left({ }^{\circ} \mathbf{C}\right) & \boldsymbol{C}_{0.5^{\mathrm{B}}}(\boldsymbol{\mu M}) \\ \text { No ligand } & 49.5 \pm 1.2 & - & - \\ \text { Compound I } & 52.1 \pm 0.9 & 2.6 & 0.7 \pm 0.1 \\ \text { Compound II } & 52.2 \pm 1.3 & 2.7 & 14.0 \pm 3.6 \\ \text { Compound III } & 63.1 \pm 2.9 & 13.6 & 5.1 \pm 1.2 \\ \text { Compound IV } & 56.7 \pm 1.5 & 7.2 & 2.6 \pm 0.4\end{array}$

AData are mean $\pm \mathrm{SD}$ from at least 3 independent experiments. Thermal upshift $\left(\Delta T_{0.5}\right)$ is calculated as the difference between the average $T_{0.5}$ values determined in the presence and absence of $100 \mu \mathrm{M}$ compound (in $2.5 \%$ DMSO) by ANS-monitored thermal unfolding. ${ }^{B} C_{0.5}$ values provide apparent binding affinities and are best-fit parameters obtained from experiments shown in Figure 2 as described in Methods. 


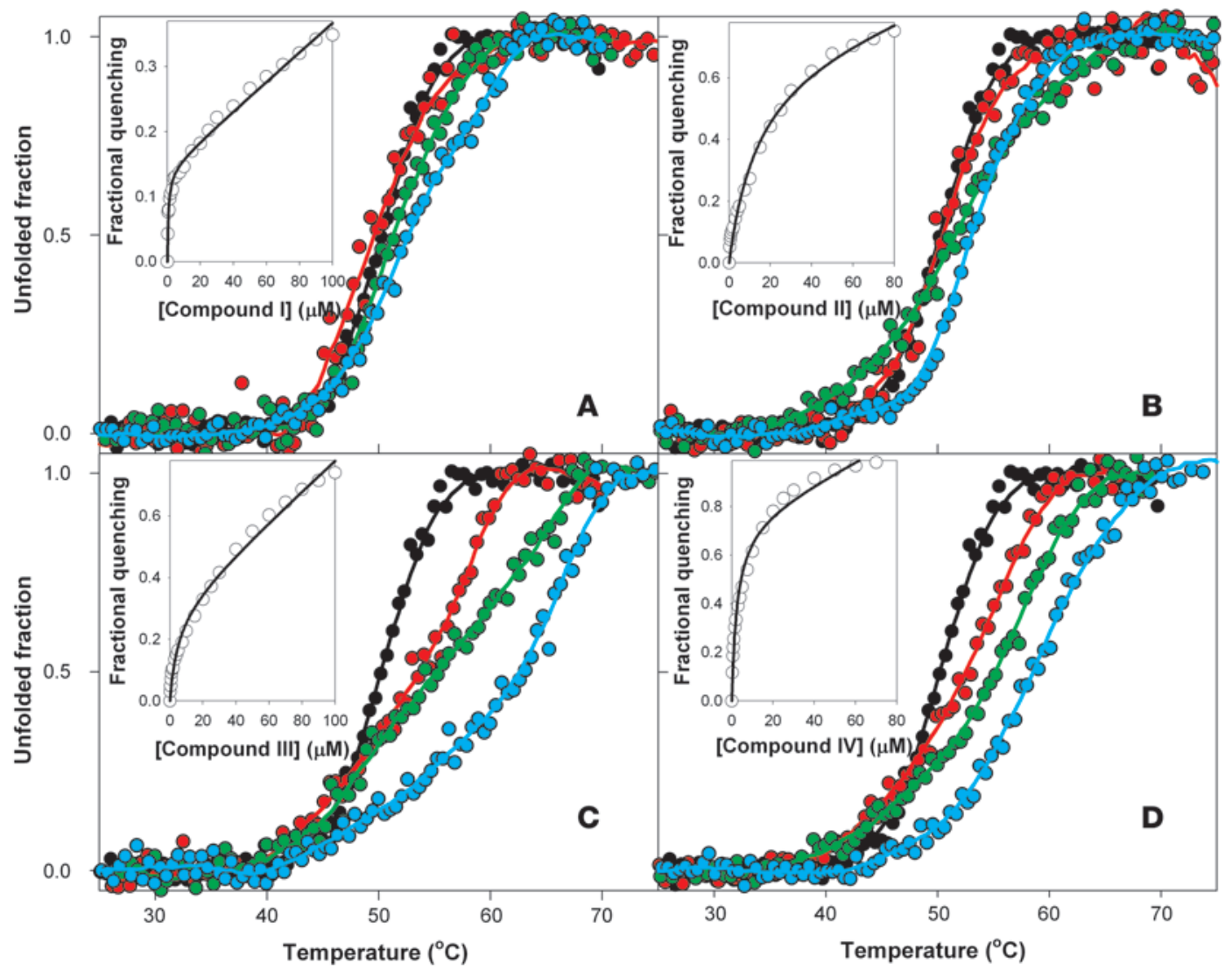

Figure 2

Representative thermal denaturation profiles of WT-PAH as monitored by ANS fluorescence in the absence or presence of different concentrations of hit compounds I (A), II (B), III (C), and IV (D). Experiments were performed using 0 (black), 25 (red), 50 (green), and 100 (light blue) $\mu \mathrm{M}$ of each compound in $2.5 \%$ DMSO. Plots are representative of at least 3 independent experiments. Insets show titrations of WT-PAH with compounds I-IV monitored by quenching of Trp-emission fluorescence spectroscopy.
$200 \mu \mathrm{M}$ were obtained for compounds I and IV, respectively, using standard equations for competitive inhibition. These $K_{i}$ values are substantially higher than those exhibited by likely physiological inhibitors of $\mathrm{PAH}$, such as $7 \mathrm{~S}-\mathrm{BH}_{4}\left(K_{\mathrm{i}} \approx 2-5 \mu \mathrm{M}\right)(25)$. Mammalian $\mathrm{PAH}$ is regulated by its substrate; the enzyme displays positive cooperativity (Hill coefficient $[h] \approx 2$ ) for L-Phe, and preincubation with the substrate leads to 3 - to 4-fold activation (Table 2) $(26,27)$. The compounds did not modify the cooperativity and activation by L-Phe and no remarkable effects on $S_{0.5}$ or $b$ were observed (Table 2). Residual activity measurements showed that at low, physiological substrate and cofactor concentrations $(\sim 100 \mu \mathrm{M}$ L-Phe and 5-10 $\mu \mathrm{M}$ $\mathrm{BH}_{4}$ with preincubation with L-Phe for 5 minutes), inhibition was observed especially for compounds I and IV at high concentrations $(100 \mu \mathrm{M})$ (Figure 3A). The inhibition was reduced when activation of the enzyme by preincubation with L-Phe was omitted (Figure $3 \mathrm{~A}$ ) and even abolished when L-Phe and $\mathrm{BH}_{4}$ were used at high concentrations, pathological for L-Phe (Figure 3B), which supports that the inhibition is reversible.

Effects of compound III and IV on the stability and folding of WT and mutant proteins. The 8-anilino 1-naphthalene sulfonic acid-based (ANS-based) thermal denaturation and fluorescence titration experiments (Figures 1 and 2) indicate that hit compounds III and IV, which are the compounds that exhibit the largest $\Delta T_{0.5}$ (Table 1), bind to the native state with relatively high affinity and only show moderate inhibition (Figure 3). We selected compounds III and IV as potential pharmacological chaperones for $\mathrm{PAH}$, and we aimed to investigate the mechanism for protein stabilization, i.e., whether the compounds stabilize PAH native state and/or facilitate the folding of partially unfolded states toward native and functional oligomeric forms. However, the lack of reversibility of both thermal and chemical PAH denaturation (data not shown) precludes the detailed investigation of chaperoning mechanisms. We, however, attempted to establish the capacity of the compounds as stabilizers of the native tetrameric functional conformation toward thermal challenge. Analysis of stabilization of correct subunit assembly of WT-PAH and 2 common PKU mutants (I65T-PAH and R68S-PAH; http://www.pahdb.mcgill.ca/) by the compounds was performed by size-exclusion chromatography (SEC) after heat shock at $50^{\circ} \mathrm{C}$ for different time periods (Figure 4A). The thermal treatment led to protein irreversible aggregation (Figure 4A). The compounds, notably compound IV, significantly decreased the estimated rate constant $(k)$ for the time-dependent loss of the tetramer in the 3 protein forms (Table 3). Accompanying thermal inactivation experiments confirmed that the tetrameric functional form is stabilized by compounds III and especially compound IV, as shown by the increase of half-inactivation temperatures $\left(T_{50}\right)$ (Figure 4, B-D, and Table 3 ).

Expression studies in transfected eukaryotic cells and coupled in vitro transcription-translation system. Preliminary cellular transfection assays indicated that cell viability was compromised at DMSO concentrations in cellular medium of more than $1 \%$, which limited the concentration of compounds III and IV to $40 \mu \mathrm{M}$ in cellular studies. We studied the transient expression of WT-PAH and the PKU mutants I65T-, R68S-, R252W- and R261Q-PAH in A293 cells for 24 hours in the absence or presence of $40 \mu \mathrm{M}$ of either compound. These 4 PKU mutations represent 4 different mutantfolding behaviors associated with different phenotypic groups in PKU patients (3): R68S is a mild mutation, I65T is mild-moderate, $\mathrm{R} 261 \mathrm{Q}$ is highly variable (mild-moderate-severe), and R252W is a 
Table 2

Enzyme kinetic parameters for WT-PAH and effect of hit compounds I-IV (100 $\mu \mathrm{M})$

\begin{tabular}{|c|c|c|c|c|c|c|c|}
\hline \multirow[t]{3}{*}{ Compound } & \multicolumn{4}{|c|}{$\mathrm{BH}_{4}{ }^{\mathrm{A}}$} & \multicolumn{3}{|c|}{$\mathrm{L}-\mathrm{Phe} \mathrm{B}^{\mathrm{B}}$} \\
\hline & \multicolumn{2}{|c|}{ Preincubation with L-Phe } & \multicolumn{2}{|c|}{ No preincubation with L-Phe } & \multirow[b]{2}{*}{$\frac{V_{\max }}{(\mu \mathrm{mol} \mathrm{L}-\mathrm{Tyr} / \mathrm{min} \times \mathrm{mg})}$} & \multirow[b]{2}{*}{$\begin{array}{c}S_{0.5} \\
(\mu \mathrm{M})\end{array}$} & \multirow[b]{2}{*}{$\begin{array}{l}\text { Hill coefficient } \\
(h)\end{array}$} \\
\hline & $\begin{array}{c}V_{\max } \\
(\mu \mathrm{mol} \mathrm{L}-\mathrm{Tyr} / \mathrm{min} \times \mathrm{mg})\end{array}$ & $\begin{array}{c}K_{\mathrm{m}} \\
(\mu \mathrm{M})\end{array}$ & $\begin{array}{c}V_{\max } \\
(\mu \mathrm{mol} \mathrm{L}-\mathrm{Tyr} / \mathrm{min} \times \mathrm{mg})\end{array}$ & $\begin{array}{c}K_{\mathrm{m}} \\
(\mu \mathrm{M})\end{array}$ & & & \\
\hline No ligand & $3.41 \pm 0.24$ & $41 \pm 8$ & $0.82 \pm 0.03$ & $23 \pm 3$ & $3.47 \pm 0.07$ & $136 \pm 5$ & $2.1 \pm 0.2$ \\
\hline Compound I & $3.52 \pm 0.41$ & $55 \pm 14$ & $0.80 \pm 0.05$ & $26 \pm 5$ & $3.02 \pm 0.08$ & $118 \pm 5$ & $2.6 \pm 0.3$ \\
\hline Compound II & $2.96 \pm 0.10$ & $36 \pm 3$ & $0.81 \pm 0.05$ & $24 \pm 4$ & $3.77 \pm 0.13$ & $156 \pm 10$ & $1.8 \pm 0.1$ \\
\hline Compound III & $2.87 \pm 0.14$ & $35 \pm 4$ & $0.86 \pm 0.03$ & $23 \pm 3$ & $3.57 \pm 0.11$ & $138 \pm 8$ & $1.9 \pm 0.2$ \\
\hline Compound IV & $3.11 \pm 0.16$ & $66 \pm 8$ & $0.85 \pm 0.07$ & $36 \pm 8$ & $2.43 \pm 0.10$ & $131 \pm 11$ & $1.6 \pm 0.2$ \\
\hline
\end{tabular}

Data are mean \pm SEM obtained from nonlinear regression analysis from 2 independent experiments, each performed in duplicate. ${ }^{A}$ Determined at $1 \mathrm{mM} L-P h e$ and variable concentrations of $\mathrm{BH}_{4}(0-200 \mu \mathrm{M})$. Samples were preincubated 5 minutes at $25^{\circ} \mathrm{C}$ without or with $1 \mathrm{mM} \mathrm{L-Phe} \mathrm{before} \mathrm{activity} \mathrm{measurements.} \mathrm{BDe-}$ termined at $75 \mu \mathrm{M} \mathrm{BH}_{4}$ and variable concentrations of L-Phe (0-1 mM). Samples were preincubated (5 minutes at $\left.25^{\circ} \mathrm{C}\right)$ at different L-Phe concentrations before activity measurements. The concentration of L-Phe at half-maximal activity $\left([S]_{0.5}\right)$ and the Hill coefficient were obtained from the fittings to the Hill equation.

severe mutation. Cells were harvested, and steady-state PAH activity and immunoreactive protein (at $51 \mathrm{kDa})$ were measured in soluble cell extracts. Except for R252W-PAH, which showed an activity below the assay detection limit $(<0.01 \mathrm{nmol} \mathrm{L-Tyr} / \mathrm{min} \times \mathrm{mg}$ protein; $<0.2 \%$ of WT-PAH), the mutants I65T-, R68S-, and R261QPAH presented relatively high activities, i.e., $23 \%, 46 \%$, and $69 \%$ of WT-PAH activity, respectively, in the absence of compounds. These results are consistent with previous expression analyses in eukaryotic systems $(\mathrm{I} 65 \mathrm{~T}=41 \% \pm 33 \%, \mathrm{R} 68 \mathrm{~S}=57 \% \pm 36 \%, \mathrm{R} 261 \mathrm{Q}=51 \% \pm 26 \%$, and $\mathrm{R} 252 \mathrm{~W}=0 \%$ as compiled in ref. 3 ); the lower protein levels and residual activities of the mutants reflect the associated folding defects. After 24 hours incubation of the cells and transient enzyme expression in the presence of the compounds, the PAH activity was increased $60 \%-100 \%$ by compound III and $40 \%-50 \%$ by compound IV in WT-, I65T-, and R68S-PAH (Figure 5A). Good correlation was found for the increases of PAH activity and immunoreactive protein (Figure $5 \mathrm{~B}$ ). In the case of $\mathrm{R} 252 \mathrm{~W}$, only an increase in $\mathrm{PAH}$ immunoreactive protein was observed in the presence of compound III (Figure 5B), while activity was too low to be accurately determined, probably due to a mixed effect of this mutation on both folding and catalytic efficiency of the PAH enzyme. The increases in PAH activity and protein were subsequently reproduced in 3-4 independent cellular experiments and were statistically significant in most cases for compound III and, in a few cases, for compound IV (Figure 5, A and B).

To further investigate the mechanism of stimulation of protein and activity levels by the compounds in cells, notably by compound III (Figure 5, A and B), protein synthesis was blocked after 18 hours with the translation inhibitor puromycin. In the presence of this inhibitor, A293 cells survived up to 9 hours, which was too brief to properly calculate the $t_{1 / 2}$ of WT-PAH by Western blot and densitometric analysis. For this protein, we could still verify that both compounds increased the level of synthesized protein (Figure 5C). On the other hand, for I65T-PAH, the conditions were very appropriate to measure the $t_{1 / 2}$, which certainly increased (about $40 \%$ ) in the presence of compound IV (Figure 5C).

It was surprising that compound III, which increases PAH activity in cells transiently expressing WT-PAH and PKU mutants with higher efficiency than compound IV (Figures 5, A and B), shows lower stabilization of the tetrameric form (Figure 4) and lower protection toward processing of $\mathrm{PAH}$ - most probably due to proteolytic degradation - than compound IV (Figure 5C). This smaller effect is not due to a lower affinity of compound III since, at least for WT-PAH, the affinities of both compounds are comparable (Table 1) and saturating concentrations are used in all experiments. We hypothesized that, while compound IV appears to bind primarily to the native tetrameric folded state, stabilizing it, compound III might exert its chaperoning activity in cells partly by another mechanism. We then investigated to determine whether the compounds might accelerate the synthesis of $\mathrm{PAH}$ using a cell-free transcription-translation system compatible with monitoring protein synthesis in short time scales, i.e., the Rapid Translation System (RTS). The expression of PAH cDNA in in vitro cell-free systems produced active protein of correct oligomeric structure with apparent $M_{\mathrm{r}}$ of approximately $51 \mathrm{kDa}$ by SDS-PAGE and autoradiography $(28,29)$. By using RTS, we were able to detect labeled WT-PAH

\section{Figure 3}

Effect of the hit compounds on the activity of recombinant WT-PAH. Activity was measured with $100 \mu \mathrm{M}$ L-Phe and $10 \mu \mathrm{M} \mathrm{BH}_{4}(\mathbf{A})$ or $1 \mathrm{mM} \mathrm{L-Phe}$ and $200 \mu \mathrm{M} \mathrm{BH}_{4}(\mathbf{B})$, in the presence of $100 \mu \mathrm{M}$ of each compound in $2.5 \%$ DMSO (also present in control sample [C]). Samples were preincubated (black bars) or not preincubated (white bars) with the corresponding L-Phe concentration for 5 minutes at $25^{\circ} \mathrm{C}$ prior to the addition of compounds and of $\mathrm{BH}_{4}$ to start activity measurements. Data are mean \pm SD of triplicate experiments.
A

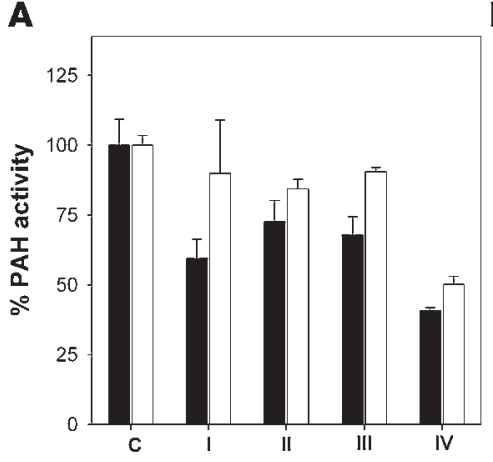

B

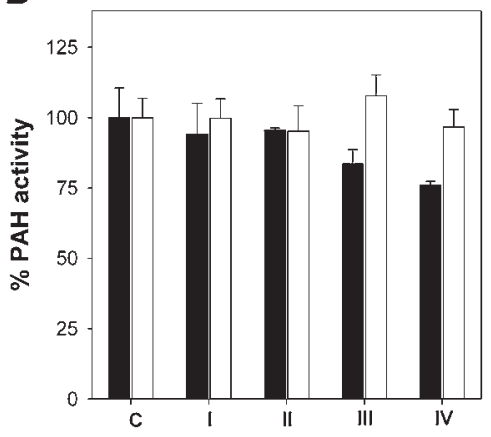


A
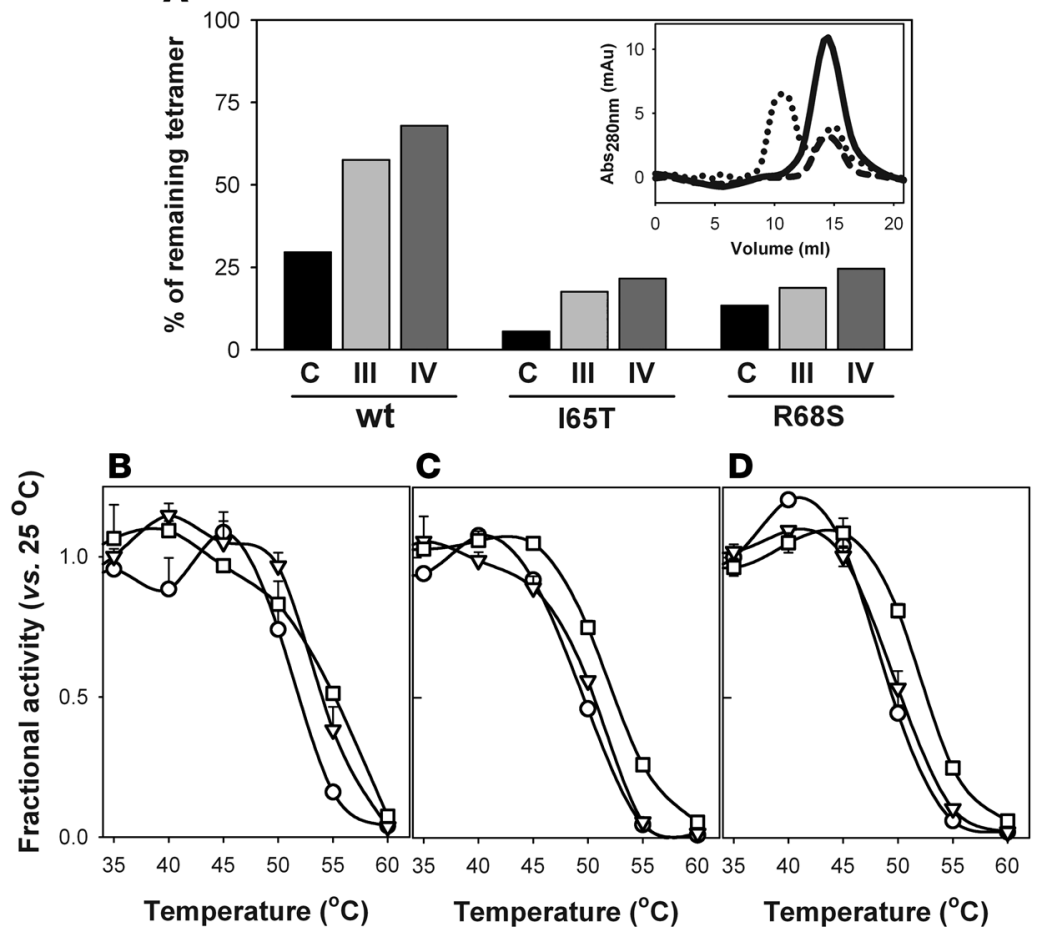

\section{Figure 4}

Effect of hit compounds III and IV on the stability and function of tetrameric PAH proteins. (A) SEC determination of the fraction of remaining tetramer in WT and mutant proteins after heat shock at $50^{\circ} \mathrm{C}$ for 20 minutes in the absence or presence of $100 \mu \mathrm{M}$ of compound III and IV in $2.5 \%$ DMSO (also present in control sample). Data are expressed as area of the tetrameric fraction after heat shock related to the area in corresponding samples incubated for 10 minutes at $25^{\circ} \mathrm{C}$. Inset shows representative SEC profiles obtained for tetrameric WT-PAH incubated at $25^{\circ} \mathrm{C}$ for 10 minutes (solid line) or for 2 independent samples treated at $50^{\circ} \mathrm{C}$ for 20 minutes with (dashed line) or without (dotted lines) filtering through a $0.22-\mu \mathrm{m}$ pore filter to remove protein aggregates. Only the aggregated forms are eliminated by filtration. Elution volumes are approximately $15 \mathrm{ml}$ for tetrameric forms and approximately $10 \mathrm{ml}$ for aggregates (the void volume of the column). (B-D) Thermal inactivation experiments (B, WT-PAH; C, I65T-PAH; D, R68S-PAH) performed by 10-minute incubation at the indicated temperatures without (circles) or with $100 \mu \mathrm{M}$ of compound III (triangles) and IV (squares) and subsequent measurement of $\mathrm{PAH}$ activity at $25^{\circ} \mathrm{C}$. Data are expressed as fractional activity after incubation at different temperatures related to the corresponding activity after incubation at $25^{\circ} \mathrm{C}$ and are given as mean $\pm S D$ of triplicate experiments. very soon after initiation of translation and to follow the kinetics of synthesis of the enzyme previous to saturation at about 40-60 minutes. Compound III, but not compound IV, certainly accelerated the synthesis of WT-PAH (Figure 5D).

Effect of compounds III and IV on hepatic PAH upon oral loading to WT mice. The results described above showed a remarkable capability of compounds III and IV to enhance WT and mutant protein levels and activity in a cellular model system, with somewhat different molecular mechanisms for stabilization by compounds III and IV. The efficacy of a therapeutic drug, however, also depends on in vivo pharmacokinetics (e.g., absorption, distribution, metabolism, and excretion of the compound, etc.), which determines the efficient drug concentration in the target organ (30) and is better evaluated in an animal model. In the present case of PKU therapy by correction of PAH misfolding, the target organ is the liver, which is highly capable of metabolizing xenobiotics. An additional interest of analyzing the effect of compounds III and IV in vivo in WT mice was thus to determine whether these compounds are able to survive the hepatic metabolic machinery for xenobiotic detoxification.

In a pilot test, the animals were treated orally with $0.25 \mathrm{mg} / \mathrm{kg} / \mathrm{d}$ of either compound III or IV over a period of 10 days, without significant changes in $\mathrm{PAH}$ protein or activity in liver (data not shown). We thus increased the dose to $5 \mathrm{mg} / \mathrm{kg} / \mathrm{d}$ of either compound over a period of 12 days. Figure 6 shows the results obtained in liver extracts for each group of mice (control versus treated animals) for PAH activity (Figure 6A) and protein levels (Figure $6 \mathrm{~B})$ in vivo. Significant increases in PAH activity and protein levels were observed for treated animals, i.e., approximately $90 \%$ and approximately $35 \%$ increases in PAH activity for treatment with compounds III and IV, respectively, versus control animal, while protein levels increased $40 \%-50 \%$ in both cases (Figure 6). At the same time, relative $P A H$ gene expression or Pab-mRNA stability did not appear to be affected as assessed by quantitative RT-PCR of Pah-mRNA expression, i.e., $1.6 \pm 0.2$ and $1.2 \pm 0.2$ for the groups treated with compounds III and IV, respectively, versus $1.4 \pm 0.3$ for the DMSO control group.

These experiments indicate that compounds III and IV are efficiently absorbed and transported to the liver and survive long enough to stabilize hepatic $\mathrm{PAH}$ protein, increasing its activity and protein levels. In so doing, they can be considered pharmacological chaperones.

\section{Discussion}

$P K U$ as a target for pharmacological chaperones. Current treatment for PKU is based on dietary restriction of L-Phe $(1,31)$. Although successful, this treatment can be a social burden, and it has to be maintained for life in many cases. Alternatively, $\mathrm{BH}_{4}$ supplementation partially combats PKU, a misfolding disease, by stabilizing some mutant $\mathrm{PAH}$ proteins and protecting them against degradation/inactivation in the presence of increased $\mathrm{BH}_{4}$ concentrations $(9,23,28)$. A recent phase III study indicates that $\mathrm{BH}_{4}$ supplementation is a safe and realistic approach (8), and this treatment could be especially relevant in treatment of mild PKU phenotypes. Our approach based on pharmacological chaperones indeed exploits the nature of PKU as a misfolding disease, since these nonphysiological compounds potentially restore $\mathrm{PAH}$ activity of the mutants in vivo. Daily oral treatment with $5 \mathrm{mg} / \mathrm{kg} / \mathrm{d}$ of compounds III and IV substantially increased PAH activity in mouse liver (1.9-fold increase in the case of compound III), with an increase slightly higher than that observed upon treatment using a 10-fold higher dose of $\mathrm{BH}_{4}$ for 5 weeks $(50 \mathrm{mg} / \mathrm{kg} / \mathrm{d}$; 1.7 -fold increase; ref. 23), while lower doses of $\mathrm{BH}_{4}(10 \mathrm{mg} / \mathrm{kg} / \mathrm{d})$ did not show significant changes in activity or protein levels (23). These results clearly show that ligands that significantly stabilized PAH in vitro (for instance versus thermal challenges) are able to increase protein levels and activity in cellular and animal models. A folding acceleration effect and a protection toward ubiquitin-mediated proteolytic degradation 


\section{Table 3}

Effect of $100 \mu \mathrm{M}$ of compounds III and IV on the correct tetrameric assembly of $5 \mu \mathrm{M}$ WT-PAH, I65T-PAH, and R68S-PAH mutants

\begin{tabular}{|c|c|c|c|}
\hline Protein & Compound & $k\left(10^{2}\right)\left(\min ^{-1}\right)^{A}$ & $T_{50}\left({ }^{\circ} \mathrm{C}\right)^{\mathrm{t}}$ \\
\hline \multirow[t]{3}{*}{ WT } & None & $6.9 \pm 0.8$ & 52.1 \\
\hline & III & $3.3 \pm 0.5$ & 54.0 \\
\hline & IV & $2.6 \pm 0.4$ & 55.2 \\
\hline \multirow[t]{3}{*}{ I65T } & None & $16.2 \pm 3.4$ & 49.6 \\
\hline & III & $11.4 \pm 1.5$ & 50.6 \\
\hline & IV & $9.2 \pm 1.0$ & 52.6 \\
\hline \multirow[t]{3}{*}{ R68S } & None & $17.0 \pm 4.6$ & 49.5 \\
\hline & III & $13.3 \pm 3.5$ & 50.4 \\
\hline & IV & $11.1 \pm 3.4$ & 52.9 \\
\hline
\end{tabular}

AFirst-order rate constants $(k)$ for tetramer decay at $50^{\circ} \mathrm{C}$ as measured by SEC. BCalculated from the inactivation experiments shown in Figure 4, B-D.

appear as likely molecular mechanisms for the chaperoning function of compounds III and IV, respectively. Both mechanisms have been described previously for pharmacological chaperones that correct in vitro misfolding mutants involved in other diseases - both discovered by screening or by structural and functional optimization of natural ligands (16-18, 20, 32).

Our HTS on a commercial chemical library of lead compounds has shown significant success in finding potentially strong pharmacological chaperones for PKU treatment (about 1 of each 500 compounds tested). Besides, by using a methodological translational-like approach, we have been able to link a simple physicochemical principle (protein stabilization by ligand binding as seen by thermal-shift assay in vitro; Figures 1 and 2) to a therapeutic principle (pharmacological chaperones that increase PAH, WT, and mutants in cells and mouse liver; Figures 5 and 6). The selected pharmacological chaperones are efficiently absorbed, transported, and delivered to the target tissue (liver) in a WT animal model, therefore showing suitable pharmacokinetic properties.

The use of PKU mouse models has offered insight into the study of different aspects of PKU and potential treatments such as enzyme replacement therapy (12). However, the available mouse strains present several drawbacks in studying pharmacological therapies based on misfolding correction. Strain Enu2, a model for severe PKU, carries the F263S mutation, which is a catalytic deleterious mutation that renders a totally inactive ( $<1 \%$ of normal) $\mathrm{PAH}$ protein (33); the catalytic defect would mask any increase in protein stability and thus is not a good model for testing misfolding correction. On the other hand, the Enu1 strain, with the V106A mutation, displays a very mild phenotype (33) with high inter- and intraanimal variation that impedes the detection of statistically significant correction of blood Phe levels and of potential responsiveness to chaperone treatment. Finally, the Enu3 strain, which shows severe classical PKU (34), is appropriate for therapeutic correction of misfolding, since it carries a splicing mutation. In the absence of a suitable mouse model for a PAH-folding variant, our studies using a normal (WT) mouse strain still provide relevant information on the pharmacokinetics of these compounds. Similar experiments carried out on WT mice have yielded insightful data on the effects of $\mathrm{BH}_{4}$ supplementation on $\mathrm{PAH}$ protein and activity and the mechanisms for $\mathrm{BH}_{4}$-responsive PKU (23).
Therapentic threshold for PAH activity in vivo and PKU metabolic correction. It is thought that there is enough $\mathrm{PAH}$ in mammalian liver to deplete plasma L-Phe within a few minutes if the enzyme becomes fully active (35). Recently, L-Phe oxidation rate measurements have shown in vivo L-Phe oxidation rates of approximately $20 \%$, approximately $40 \%$, and approximately $60 \%$ for classic PKU, mild PKU, and mild hyperphenylalaninemia patients, respectively, compared with control subjects (7). The same report showed that a reduction of plasma L-Phe to therapeutic levels in PKU patients subjected to $\mathrm{BH}_{4}$ oral loads is accomplished by a modest average increase of approximately 2.5 -fold in L-Phe oxidation in vivo in patients showing mild hyperphenylalaninemia and mild phenotypes (7). These studies combined with experiments in mice (23) indicate that a moderate pharmacological increase in PAH activity (2-fold) may lead to a substantial correction of the clinical phenotype. Similarly, our results show that relatively low doses $(5 \mathrm{mg} / \mathrm{kg} / \mathrm{d})$ of compounds III and IV are able to enhance PAH activity in mice (up to 2-fold for compound III, which appears to be the most effective). This finding suggests that administration of these chaperones could assist PAH activity levels in reaching a therapeutic range, leading to substantial reduction in plasma L-Phe concentrations, at least in the milder forms of the disease. Similar low levels of residual enzyme activity and function gained by misfolding correction by pharmacological chaperones (5\%-10\% of normal levels) have also been shown to prevent disease in lysosomal storage diseases (32).

Compounds III and IV as leads for drug optimization. The present results with compounds I-IV, notably III and IV, provide a basis for developing more potent pharmacological chaperones based on these lead structures. From a medicinal chemistry viewpoint, optimization of these - most probably catalytically inert - lead compounds is easier to accomplish than, for instance, optimization of the natural cofactor. Rational modification of $\mathrm{BH}_{4}$ to improve binding affinity may affect its catalytic efficiency and reaction coupling, leading to suboptimal cofactor properties or even to a pterin compound exhibiting inhibitory properties on PAH (36). The fact that compound III does not display significant inhibitory effect indicates that the compound might be modified in order to increase its affinity for PAH. This would enhance its potency as pharmacological chaperone, therefore allowing potentially larger correction of the phenotype while still using relatively low concentrations. Further improvement of the binding affinity of compound III might also lead to enhanced stimulation of PAH protein and activity in severe forms of the disease (represented by the mutant R252W-PAH in our study). On the other hand, compound IV exerts an inhibitory effect on PAH. Some of the most effective pharmacological chaperones resemble active site inhibitors, and using them has been described as a counterintuitive therapeutic approach $(32,37)$. Studies with lysosomal storage disorders show that the gain in function achieved by misfolding correction counteracts and overcomes the inhibition by the chaperones (32). This is probably due to the fact that the critical threshold of residual enzyme activity for disease manifestation is much lower than the normal (WT) level. In addition, active site inhibitors usually inhibit competitively versus the natural substrates and agonists, which allows achievement of a therapeutic activity threshold in vivo at locations and conditions with high concentrations of substrates. Accordingly, the inhibition by compound IV was found to be much lower at higher (pathological) concentrations of L-Phe (Figure 3). 
A

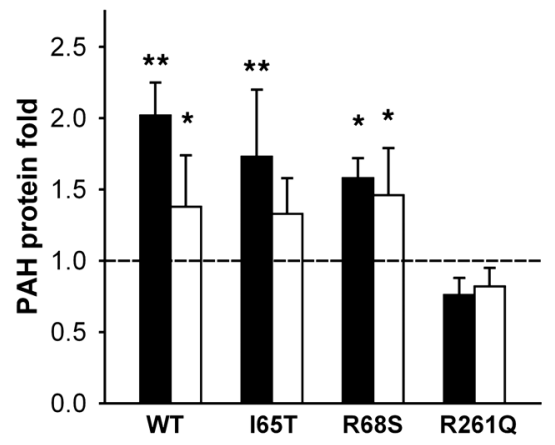

C

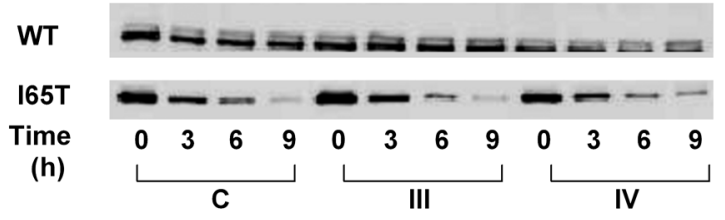

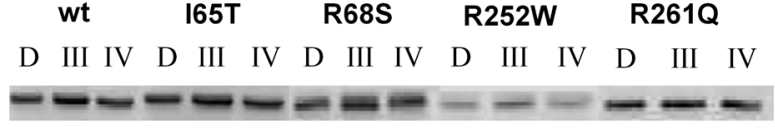

D

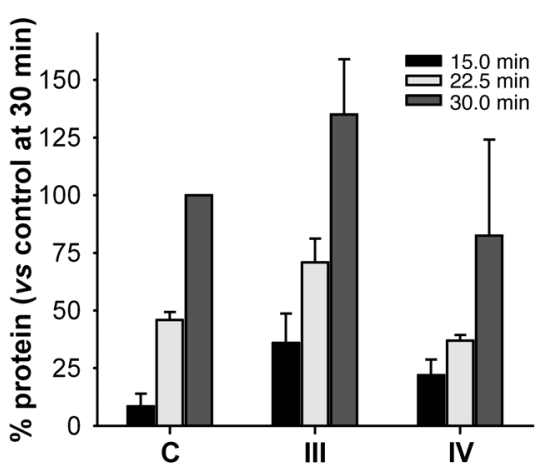

Figure 5

Effect of stabilizing hit compounds on the activity, protein level, and kinetics of degradation/synthesis of WT-PAH and PKU mutants. (A and B) Effect of compounds III (black bars) and IV (white bars) on activity (A) and protein measured by Western blot (B) of WT-PAH and PKU mutants transiently expressed (24 hours) in A293 cells. Values are given as mean \pm SD of 3-4 independent expression experiments and are compared with controls for the corresponding PAH protein, with specific activities (nmol L-Tyr/min $\times \mathrm{mg}): 7.1 \pm 2.3(\mathrm{WT}-\mathrm{PAH}), 1.7 \pm 0.6(\mathrm{I} 65 \mathrm{~T}-\mathrm{PAH})$, $3.3 \pm 0.4$ (R68S-PAH), and $4.9 \pm 1.9$ (R261Q-PAH). The activity of R252W-PAH was $<0.01 \mathrm{nmol}$ L-Tyr/min $\times$ mg protein (the detection limit) under all conditions tested and thus not considered reliable. ANOVA tests, ${ }^{\star} P<0.05 ;{ }^{* \star} P<0.01$. (C) Western blot analysis of the degradation of WT-PAH and I65T-PAH after transient transfection of A293 cells (18 hours) followed by inhibition of protein translation by puromycin (10 $\mu \mathrm{g} / \mathrm{ml})$. The half-lives $\left(t_{1 / 2}\right)$ for I65T-PAH (in hours) were $5.0 \pm 1.0$ (control), $4.8 \pm 1.1$ (with compound III), and $6.8 \pm 0.8$ (with compound IV). (D) Kinetics of synthesis of WT-PAH in cell-free RTS without and with compounds III and IV. Data (given as mean \pm SD of 3-4 independent experiments) refer to labeled PAH synthesized after 15.0 (black), 22.5 (light gray), and 30.0 (dark gray) minutes, measured by densitometry and normalized with respect to the corresponding control sample after 30-minute synthesis in the absence of compounds (100\%). In all experiments, compounds are present at $40 \mu \mathrm{M}$ in $1 \% \mathrm{DMSO}$, which is also added in control samples.

Finally, it should be noted that the affinity of a given ligand for mutant proteins is not expected to be always the same as for WTPAH due to potential effects of the mutations on the ligand-binding site. Mutational effects on ligand-binding affinity could explain the lower response for some mutations upon expression in A293 cells (e.g., R261Q-PAH), while other mutants show ligand-binding effects similar to those for WT-PAH (e.g., I65T- and R68S-PAH; Figure 5A). It is therefore possible to envision that a mutation-specific screening on a cellular system might select more specific ligands for individual patients, who usually show 2 different alleles (compound heterozygotes) (see references in ref. 3). Overall, our results show that pharmacological chaperones are a realistic therapeutic approach to restoring PAH activity for mild (and potentially for severe) PKU mutations. Further screening and optimization of binding affinities and stabilizing effects may lead to more potent compounds to be further assayed in cell and animal models and to selection of specific pharmacological chaperones to be used depending on the genotype of the patients, leading to a patient-tailored therapy for PKU.

\section{Methods}

Materials. The mutations I65T, R68S, R252W, and R261Q were introduced in the human PAH cDNA on the pcDNA3-PAH and pMALc2-PAH expression vectors (38) by PCR-based site-directed mutagenesis using the QuikChange kit (Stratagene). The primers used for mutagenesis were provided by MWG Biotech AG. The authenticity of the mutagenesis was verified by DNA sequencing using the primers reported (39).

Recombinant expression of PAH in Escherichia coli. The tetrameric fulllength human WT-PAH and I65T and R68S mutants were recombinantly expressed in E. coli as fusion proteins with maltose-binding protein and further cleaved and isolated to homogeneity without the maltose-binding protein fusion partner essentially as described (38).

HTS of ligand binding. HTS for ligand-induced PAH stabilization was performed by monitoring the thermal denaturation of recombinant pure PAH protein in the presence of the extrinsic fluorescent probe ANS (SigmaAldrich). HTS experiments were performed in a FluoDia T70 High Temperature Fluorescence Microplate Reader (PTI). Protein-ligand solutions $(200 \mu \mathrm{l})$ were dispensed into 96-well microplates (ThermoFast 96 skirted 

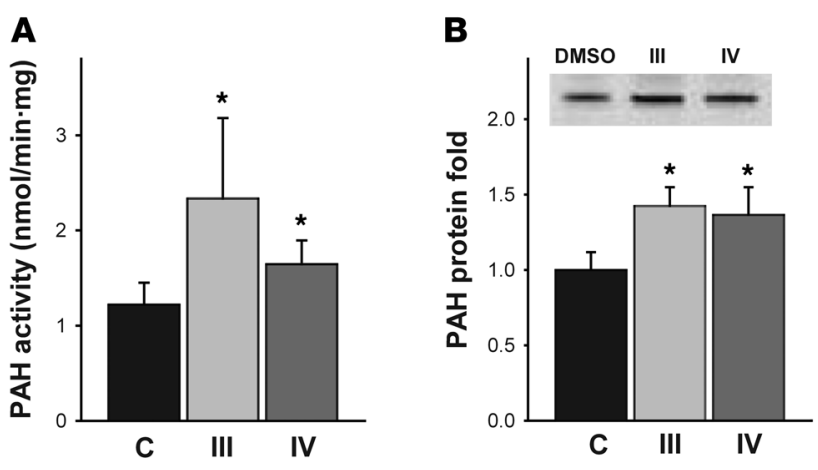

Figure 6

Effect of the hit compounds III and IV on PAH activity (A) and immunoreactive protein levels determined by Western blot (B) after 12-day administration of $5 \mathrm{mg} / \mathrm{kg} / \mathrm{d}$ to WT C57BL/6 mice. The control group was fed with a placebo containing $10 \%$ DMSO in water. PAH activities are given as mean \pm SD for each group $(n=5)$. Immunoreactive $\mathrm{PAH}$ are represented as ratios between the signal obtained for each liver extract from treated animals and the average signal in the control group (and expressed as mean \pm SD for each group; $n=5$ ). Statistically significant differences between treated and control groups are based on ANOVA tests and expressed as ${ }^{*} P<0.05$.

from Thermo Scientific) and overlaid with mineral oil. Protein solutions contained $0.1 \mathrm{mg} / \mathrm{ml}$ PAH ( $2 \mu \mathrm{M}$ PAH subunit) in $20 \mathrm{mM}$ NaHepes, $200 \mathrm{mM} \mathrm{NaCl}, \mathrm{pH}$ 7.0, and $100 \mu \mathrm{M}$ ANS. Ligands (from the Maybridge HitFinder Collection database; Maybridge Ltd.) dissolved in DMSO were manually added at $100 \mu \mathrm{M}$ and $2.5 \%$ final concentrations, respectively, to microplates containing the protein solutions and incubated at $25^{\circ} \mathrm{C}$ for 30 minutes before loading onto the microplate reader. Control experiments in the absence of DMSO and/or ligands were routinely performed in each microplate. Thermal denaturation was monitored by following the increase in ANS fluorescence intensity associated with protein unfolding $\left(\lambda_{\text {exc }}=395\right.$ and $\lambda_{\text {em }}=500 \mathrm{~nm}$, where $\lambda_{\text {exc }}$ is excitation wavelength and $\lambda_{\mathrm{em}}$ is emission wavelength; ref. 22). Unfolding curves were registered from 25 to $75^{\circ} \mathrm{C}$, at a $1^{\circ} \mathrm{C} / \mathrm{min}$ scan rate; the system was allowed to equilibrate at each temperature for 1 minute before fluorescence acquisition. In practice, this represents an operational heating rate of about $0.25^{\circ} \mathrm{C} / \mathrm{min}$.

The experimental unfolding curves were smoothed, normalized, and analyzed using homebuilt software. The fraction of unfolded protein $\left(\chi_{u}\right)$ was determined as follows: $\chi_{\mathrm{U}}=\left[F-\left(F_{N}+m_{N} \times T\right)\right] /\left[\left(F_{\mathrm{U}}+m_{\mathrm{U}} \times T\right)-\left(F_{N}+m_{N} \times T\right)\right]$ (Equation 1), where $F$ is the experimental fluorescence, $T$ is the temperature (in ${ }^{\circ} \mathrm{C}$ ), $F_{N}$ and $F_{U}$ are the fluorescence values of the native and unfolded states, respectively, at a reference $T=0{ }^{\circ} \mathrm{C}$, and $m_{N}$ and $m_{U}$ are the slopes of their linear temperature dependencies. $T_{0.5}$ was calculated as the $T$ value at which half of the protein molecules are in the unfolded state $\left(\chi_{u}=0.5\right)$.

Those compounds that increased the $T_{0.5}$ values of PAH beyond $2 \times$ the $\mathrm{SD}$ of the $T_{0.5}$ values determined in the corresponding control experiments (4-8 experiments with no added ligand performed in the same microplate), i.e., $T_{0.5 \text { (hit) }}>T_{0.5 \text { (control) }}+2 \times \mathrm{SD}$, were considered as potential positives. The original curves of the potential positives were then individually fitted to a 2 -state thermal unfolding equation (as described in ref. 40) in order to discard false positives generated during the automated analysis.

Thermal denaturation monitored by ANS fluorescence and measurement of apparent ligand affinity by quenching of intrinsic tryptophan emission fluorescence. More detailed analyses on the effect of the screening hits on the thermal denaturation of $\mathrm{PAH}$ were performed by monitoring the ANS fluorescence using a Cary Eclipse fluorescence spectrophotometer equipped with a tem- perature-controlled Peltier multicell holder (Varian). Samples containing PAH in $20 \mathrm{mM}$ NaHepes, $200 \mathrm{mM} \mathrm{NaCl}$, pH 7.0, $100 \mu \mathrm{M}$ ANS, $2.5 \%$ DMSO, and $0-100 \mu \mathrm{M}$ ligands were incubated at room temperature for 30 minutes. Thermal denaturation was then monitored by following the ANS fluorescence emission ( $\lambda_{\text {exc }}=295$ and $\lambda_{\text {em }}=500 \mathrm{~nm}$; slits, $10 \mathrm{~nm}$ ) at $1{ }^{\circ} \mathrm{C} / \mathrm{min}$ from 20 to $80^{\circ} \mathrm{C}$, using 4 different samples and including controls in the absence of ligand. Data analysis was performed by fitting the experimental fluorescence to Equation $1 . \Delta T_{0.5}$ was calculated as the difference in average $T_{0.5}$ values obtained with and without ligand.

Apparent affinity of ligand binding was studied on samples of $\mathrm{PAH}$ ( $1 \mu \mathrm{M}$ subunit) in $20 \mathrm{mM}$ NaHepes, $200 \mathrm{mM} \mathrm{NaCl}, \mathrm{pH}$ 7.0, 2.5\% DMSO, and $0-100 \mu \mathrm{M}$ of the compounds and incubated at room temperature for 30 minutes to allow equilibration prior to measurements. Intrinsic tryptophan fluorescence spectra were acquired at $25^{\circ} \mathrm{C}$ with $\lambda_{\text {exc }}=295 \mathrm{~nm}(5-\mathrm{nm}$ slit) and emission from 300 to $400 \mathrm{~nm}$ (5-nm slit). Spectra were corrected for blank emission. Fractional quenching values in the presence of the ligands were calculated from the decrease in fluorescence at $340 \mathrm{~nm}$ at increasing ligand concentrations compared with samples without ligand, as reported earlier to determine the binding affinity of different pterins to $\mathrm{PAH}(25)$. $C_{0.5}$ was estimated from fittings to a hyperbolic function, including a linear term for inner filter effects: $F=\mathrm{a} \times[L]+\left(\left(F_{\max } \times[L]\right) /\left(C_{0.5}+[L]\right)\right)$, where $F$ is the experimental fractional quenching, $[L]$ is the total ligand concentration, $F_{\max }$ is the predicted maximal quenching due to specific ligand binding, and a is a constant that describes the ligand concentration dependence of the inner-filter effect.

Enzyme kinetics. PAH activity on isolated recombinant enzymes was measured at $25^{\circ} \mathrm{C}$ for 1 minute with quantification of L-Tyr formed by HPLC with fluorimetric detection, essentially as described (38). Tetrameric human PAH (1-2 $\mu \mathrm{g})$ was incubated in $20 \mathrm{mM}$ NaHepes, $0.2 \mathrm{M} \mathrm{NaCl}$, pH 7.0, containing catalase $(0.04 \mathrm{mg} / \mathrm{ml}), 0.1-1 \mathrm{mM}$ L-Phe, $2.5 \%$ DMSO, and 0-100 $\mu \mathrm{M}$ of each compound. After 4 minutes preincubation at $25^{\circ} \mathrm{C}$, ferrous ammonium sulfate $(100 \mu \mathrm{M})$ was added and the reaction triggered after 1 minute by adding $\mathrm{BH}_{4}$ (Schircks Laboratories) $(10-200 \mu \mathrm{M})$ and $5 \mathrm{mM}$ DTT. When indicated, the preincubation step with L-Phe was omitted and the substrate was added together with $\mathrm{BH}_{4}$. The apparent $K_{m}$ values $\left(\mathrm{BH}_{4}\right)$ were determined with $\mathrm{BH}_{4}$ at $0-200 \mu \mathrm{M}$ (at $1 \mathrm{mM}$ L-Phe) and the $S_{0.5}$ values (L-Phe) at $0-1 \mathrm{mM}$ substrate (at $75 \mu \mathrm{M} \mathrm{BH}_{4}$ ). The saturation curves were fitted to hyperbolic (for $\mathrm{BH}_{4}$ ) or sigmoidal (for L-Phe) kinetic models with SigmaPlot v. 9.0. (SPSS). Kinetic parameters are presented as mean \pm SEM obtained from nonlinear regression analysis. A similar assay was used to measure $\mathrm{PAH}$ activity in cells or mouse liver extracts (see below) using $1 \mathrm{mM} \mathrm{L}$-Phe and $200 \mu \mathrm{M} \mathrm{BH}_{4}$ with 30 -minute (cell extracts) or 2-minute reactions (liver extracts). Free amino acids and contaminants of low molecular weight were previously removed from the extracts using Zebra Desalt Spin columns (Pierce Biotechnology). 5-20 $\mu \mathrm{g}$ of total protein was used for activity measurements. Under these conditions, PAH activity was linear to the amount of protein in the extracts.

For inactivation experiments complemented with SEC analyses, WT-PAH and mutants (I65T and R68S) were prepared at $5 \mu \mathrm{M}$ (in subunit) in $20 \mathrm{mM}$ NaHepes, $200 \mathrm{mM} \mathrm{NaCl}, \mathrm{pH}$ 7.0, and 2.5\% DMSO and incubated with or without $100 \mu \mathrm{M}$ of compounds III or IV at $25^{\circ} \mathrm{C}$ for 10 minutes to allow equilibration. Aliquots were then transferred to a thermal block at $25-60^{\circ} \mathrm{C}$ and incubated for 10 minutes (for measurement of remaining activity) or for 5-40 minutes (for determination of remaining tetramer). After incubation, the samples were chilled on ice for 10 minutes and subsequently analyzed for remaining activity (see above) at each incubation temperature with respect to that of samples incubated at $25^{\circ} \mathrm{C}$. Experiments were performed in triplicate. $T_{50}$ indicates the temperatures for $50 \%$ of residual activity calculated by linear interpolation. For SEC analysis, the samples were filtered through $0.22-\mu \mathrm{m}$ filters to remove precipitates of protein and/or ligand and then injected into a 10/30 Superdex 200 column (Amersham) previously 
calibrated with proteins of known Stokes radii and with blue dextran and acetone to determine the retention times for the native tetrameric $\mathrm{PAH}$ and the void and total volumes, respectively. Apparent first-order rate constants (k) for tetramer disappearance (due to aggregation) were calculated by fitting the values of remaining tetramer (\%) vs. incubation time to a single exponential decay function.

Coupled in vitro transcription-translation system. Selective synthesis of $\left.{ }^{35} \mathrm{~S}\right]$-labeled human $\mathrm{PAH}$ was obtained at $37^{\circ} \mathrm{C}$ by in vitro transcriptiontranslation using the Rapid Translation System (RTS) (RTS ProteoMaster 500; Roche Molecular Biochemicals) with the enhanced E. coli lysate and ${ }^{35} \mathrm{~S}$-L-Met (Amersham) and the expression vector pcDNA3-WT-PAH in the absence and presence of compounds III and IV $(40 \mu \mathrm{M})$ in $1 \%$ DMSO. $1 \% \mathrm{DMSO}$ was also present in control synthesis assays. Aliquots were taken from the synthesis assays at indicated times. Unlabeled L-Met $(5 \mathrm{mM})$, ribonuclease $\mathrm{A}(1 \mathrm{mg} / \mathrm{ml})$, and DNase $(1 \mathrm{mg} / \mathrm{ml})$ were added, and the aliquots were analyzed for PAH protein by SDS-PAGE and autoradiography.

Expression of WT and mutant PAH in eukaryotic cells. Human embryonic kidney cells (A293; Invitrogen) were grown in DMEM containing $4.5 \mathrm{~g} / 1$ glucose, $10 \%(\mathrm{v} / \mathrm{v})$ fetal calf serum, $2 \mathrm{mM}$ L-glutamine, $100 \mathrm{IU} / \mathrm{ml}$ penicillin, $100 \mu \mathrm{g} / \mathrm{ml}$ streptomycin, and $0.25 \mathrm{mg} / \mathrm{ml}$ Geneticin (Gibco; Invitrogen). A293 cells were transiently transfected with $1 \mu \mathrm{g}$ of pcDNA3-PAH vector (WT or mutant PAH constructs) using the Lipofectamine system (Gibco; Invitrogen) as described by the manufacturer. Compounds III and IV were added after 5 hours of transfection at $40 \mu \mathrm{M}$ final concentration in $1 \%$ DMSO and incubated for 24 hours, at which time the cells were harvested and stored at $-80^{\circ} \mathrm{C}$. Control experiments revealed no significant effects of $1 \%$ DMSO either on cell growth and survival or on PAH activity and immunoreactivity (data not shown). To prepare the cell extracts, the frozen cell pellets were thawed in PBS buffer, $\mathrm{pH}$ 7.4, containing $50 \mathrm{mM}$ sucrose and $0.2 \mathrm{mM}$ PMSF, chymostatin, leupeptin, antipain, and pepstatin $(10 \mu \mathrm{g} / \mathrm{ml}$ each), and cells were homogenized by 20 passages using a fine needle. Sucrose concentration was then raised to $0.25 \mathrm{M}$ and extracts were clarified by centrifugation at $170,000 \mathrm{~g}$ for 30 minutes at $4^{\circ} \mathrm{C}$. Protein concentrations were normalized using Bradford assays (41).

For turnover experiments and determination of half-lives of the protein $\left(t_{1 / 2}\right)$, transient expression was carried out for 18 hours in the absence or presence of compounds III and IV and protein synthesis was then stopped by addition of $10 \mu \mathrm{g} / \mathrm{ml}$ puromycin to the medium. Cells were harvested at time points up to 9 hours and analyzed by Western blotting. Relative protein amounts were determined by densitometric analysis.

Experiments with mice. Animal experiments were carried out in accordance with the State Veterinary Office of Zurich and Swiss law on animal protection, the Swiss Federal Act on Animal Protection (1978), and the Swiss Animal Protection Ordinance (1981). All animal studies were approved by the Cantonal Veterinary Office, Zurich, and the Cantonal Committee for Animal Experiments, Zurich. Young adult female C57BL/6 mice (12 weeks old; 20-25 g) were kept on normal diets and loaded with a $25 \mu$ l suspension containing (a) $0.25 \mathrm{mg} / \mathrm{ml}$ (about $0.7 \mathrm{mM}$ ) and (b) $5 \mathrm{mg} / \mathrm{ml}$ (about $14 \mathrm{mM}$ ) of either compound III or IV in 10\% DMSO and 9\% glucose for 12 days. This provided doses of (a) $0.25 \mathrm{mg} / \mathrm{kg} / \mathrm{d}$ and (b) $5 \mathrm{mg} / \mathrm{kg} / \mathrm{d}$. Groups of 5 animals were treated, including a control group loaded with DMSO and glucose. Approximately 30 minutes after the last dose, the animals were sacrificed with $\mathrm{CO}_{2}$ and livers were removed and frozen in liquid nitrogen. Liver extracts were prepared by homogenization in 4 volumes of $50 \mathrm{mM}$
TrisHCl, pH 7.0, $100 \mathrm{mM} \mathrm{KCl}, 1 \mathrm{mM}$ EDTA and $1 \mathrm{mM}$ DTT, $1 \mu \mathrm{M}$ leupeptin, $1 \mu \mathrm{M}$ pepstatin, and $200 \mu \mathrm{M}$ PMSF. Extracts were clarified by ultracentrifugation at $40,000 \mathrm{~g}$ for 30 minutes at $4^{\circ} \mathrm{C}$, and supernatants were stored in liquid nitrogen prior to use. Protein concentration was measured by the Bradford method (41).

Western blot and quantitative RT-PCR analyses. Western blot analyses were performed on either cell extracts from transfected A293 cells or mouse liver extracts after SDS-PAGE (10\% acrylamide) with 5-10 $\mu \mathrm{g}$ total protein in each lane. A polyclonal mouse anti-human PAH (PH8; Chemicon) at $1 \mu \mathrm{g} / \mathrm{ml}$ was used as primary antibody and a goat anti-mouse HRP conjugate (Bio-Rad) as secondary antibody. Purified recombinant human PAH (1-10 ng/lane) was used as standard for immunoquantification. Detection was performed by chemiluminescence (ECL; Amersham), and immunoquantification in a Fluor-S MultiImager (Bio-Rad) using Quantity One v. 4.5.2 software.

For quantitative RT-PCR determination of $P a b$ mRNA, approximately $30 \mathrm{mg}$ of mouse liver was used for isolation of RNA with the QIAamp RNA Blood Mini Kit from QIAGEN. Random primed cDNA was prepared from $1 \mu \mathrm{g}$ total RNA using the Reverse Transcription System from Promega. Quantitative PCR was performed in standard triplicate assays with $50 \mathrm{ng}$ of cDNA using TaqMan technology and an ABI Prism 7700 sequence detector and the TaqMan Universal PCR Master Mix from ABI. Detailed information about the specific transcript detection cannot be given, as we used ABI TaqMan Gene Expression Assays, which are under proprietary license, and the exact primer and probe sequence are not available. The ABI assay number for mouse PahmRNA was Mm00500918_ml (NCBI nucleotide sequence number NM_ 00877.1). For control, the murine Gapdh gene was used (ABI assay ID Mm99999915_gl; NCBI nucleotide sequence number NM_008084.2).

Statistics. Data are presented as mean \pm SEM when they are obtained from nonlinear regression analysis and as mean \pm SD when they are obtained from independent measurements. Tests for statistical significance were performed using 1-way ANOVA. $P<0.05$ was considered significant.

\section{Acknowledgments}

We want to thank Randi M. Svebak and Ali J. Sepulveda Muñoz for expert technical assistance. This research has been supported by grants from the Research Council of Norway and Helse-Vest (to A. Martinez) and by grants BFU2007-61476/BMC, SAF200407722, and CTQ2005-00360/BQU (Spain) and PM076/2006 (Aragón, Spain) (to J. Sancho and A. Velazquez-Campoy), and the Swiss National Science Foundation (to B. Thöny). N. Cremades was supported by MEC fellowships (Spain). A. Velazquez-Campoy is a recipient of a Ramón y Cajal Research Contract (Spain).

Received for publication October 29, 2007, and accepted in revised form May 14, 2008.

Address correspondence to: Aurora Martinez, University of Bergen, Jonas Lies vei 91, Bergen 5009, Norway. Phone: 47-55-58-64-27; Fax: 47-55-58-63-60; E-mail: aurora.martinez@biomed.uib.no. Or to: Javier Sancho, Department of Biochemistry and Molecular and Cellular Biology, Universidad de Zaragoza, Pedro Cerbuna 12, 50009 Zaragoza, Spain. Phone: 00-34-976-76-1286; Fax: 00-34976-76-2123; E-mail: jsancho@unizar.es.
21:333-344.

3. Pey, A.L., Stricher, F., Serrano, L., and Martinez, A. 2007. Predicted effects of missense mutations on native-state stability account for phenotypic outcome in phenylketonuria, a paradigm of misfolding diseases. Am. J. Hum. Genet. 81:1006-1024.

4. Matalon, K.M. 2006. Dietary recommendations in the USA. In PKU and BH4. Advances in phenylketonuria and tetrabydrobiopterin. N. Blau, editor. SPS Verlagsgesellschaft. Heilbronn, Germany. 220-231.

5. NIH Consensus Development Panel. 2001. National Institutes of Health Consensus Development Conference Statement. Phenylketonuria: screening and management, October 16-18, 2000. Pediatrics. 
108:972-982

6. Blau, N., and Erlandsen, H. 2004. The metabolic and molecular bases of tetrahydrobiopterinresponsive phenylalanine hydroxylase deficiency. Mol. Genet. Metab. 82:101-111.

7. Muntau, A.C., et al. 2002. Tetrahydrobiopterin as an alternative treatment for mild phenylketonuria. N. Engl. J. Med. 347:2122-2132.

8. Levy, H.L., et al. 2007. Efficacy of sapropterin dihydrochloride (tetrahydrobiopterin, 6R-BH4) for reduction of phenylalanine concentration in patients with phenylketonuria: a phase III randomised placebo-controlled study. Lancet. 370:504-510.

9. Erlandsen, H., et al. 2004. Correction of kinetic and stability defects by tetrahydrobiopterin in phenylketonuria patients with certain phenylalanine hydroxylase mutations. Proc. Natl. Acad. Sci. U. S. A. 101:16903-16908.

10. Kure, S., et al. 2004. Wild-type phenylalanine hydroxylase activity is enhanced by tetrahydrobiopterin supplementation in vivo: an implication for therapeutic basis of tetrahydrobiopterin-responsive phenylalanine hydroxylase deficiency. Mol. Genet. Metab. 83:150-156.

11. Matalon, R., et al. 2003. Future role of large neutral amino acids in transport of phenylalanine into the brain. Pediatrics. 112:1570-1574.

12. Gamez, A., et al. 2005. Development of pegylated forms of recombinant Rhodosporidium toruloides phenylalanine ammonia-lyase for the treatment of classical phenylketonuria. Mol. Ther. 11:986-989.

13. Chen, L., and Woo, S.L. 2005. Complete and persistent phenotypic correction of phenylketonuria in mice by site-specific genome integration of murine phenylalanine hydroxylase cDNA. Proc. Natl. Acad. Sci.U.S. A. 102:15581-15586.

14. Ding, Z., et al. 2008. Correction of murine PKU following AAV-mediated intramuscular expression of a complete phenylalanine hydroxylating system. Mol. Ther. 16:673-681.

15. Gregersen, N., Bross, P., Vang, S., and Christensen, J.H. 2006. Protein misfolding and human disease. Annu. Rev. Genomics Hum. Genet. 7:103-124.

16. Ulloa-Aguirre, A., Janovick, J.A., Brothers, S.P., and Conn, P.M. 2004. Pharmacologic rescue of conformationally-defective proteins: implications for the treatment of human disease. Traffic. 5:821-837.

17. Cohen, F.E., and Kelly, J.W. 2003. Therapeutic approaches to protein-misfolding diseases. Nature.
426:905-909.

18. Johnson, S.M., et al. 2005. Native state kinetic stabilization as a strategy to ameliorate protein misfolding diseases: a focus on the transthyretin amyloidoses. Acc. Chem. Res. 38:911-921.

19. Arakawa, T., Ejima, D., Kita, Y., and Tsumoto, K. 2006. Small molecule pharmacological chaperones: From thermodynamic stabilization to pharmaceutical drugs. Biochim. Biophys. Acta. 1764:1677-1687.

20. Loo, T.W., and Clarke, D.M. 2007. Chemical and pharmacological chaperones as new therapeutic agents. Expert. Rev. Mol. Med. 9:1-18.

21. Kolter, T., and Sandhoff, K. 2006. Sphingolipid metabolism diseases. Biochim. Biophys. Acta. 1758:2057-2079.

22. Matulis, D., Kranz, J.K., Salemme, F.R., and Todd, M.J. 2005. Thermodynamic stability of carbonic anhydrase: measurements of binding affinity and stoichiometry using ThermoFluor. Biochemistry. 44:5258-5266

23. Scavelli, R., et al. 2005. Stimulation of hepatic phenylalanine hydroxylase activity but not PahmRNA expression upon oral loading of tetrahydrobiopterin in normal mice. Mol. Genet. Metab. 86(Suppl. 1):S153-S155.

24. Thórólfsson, M., et al. 2002. L-phenylalanine binding and domain organization in human phenylalanine hydroxylase: a differential scanning calorimetry study. Biochemistry. 41:7573-7585.

25. Pey, A.L., et al. 2006. Specific interaction of the diastereomers 7(R)- and 7(S)-tetrahydrobiopterin with phenylalanine hydroxylase: implications for understanding primapterinuria and vitiligo. FASEB J. 20:2130-2132.

26. Kaufman, S. 1993. The phenylalanine hydroxylating system. Adv. Enzymol. Relat. Areas Mol. Biol. 67:77-264.

27. Pey, A.L., and Martínez, A. 2006. The Phenylalanine Hydroxylase System. In PKU and BH4. Advances in phenylketonuria and tetrabydrobiopterin. N. Blau, editor. SPS Verlagsgesellschaft. Heilbronn, Germany. 49-74.

28. Pey, A.L., et al. 2004. Mechanisms underlying responsiveness to tetrahydrobiopterin in mild phenylketonuria mutations. Hum. Mutat. 24:388-399.

29. Thony, B., Ding, Z., and Martinez, A. 2004. Tetrahydrobiopterin protects phenylalanine hydroxylase activity in vivo: implications for tetrahydrobiopterin-responsive hyperphenylalaninemia. FEBS Lett.
577:507-511

30. Castell, J.V., Jover, R., Martinez-Jimenez, C.P., and Gomez-Lechon, M.J. 2006. Hepatocyte cell lines: their use, scope and limitations in drug metabolism studies. Expert Opin. Drug Metab. Toxicol. 2:183-212.

31. Matalon, R., and Michals-Matalon, K. 2006. Treatment of phenylketonuria variants: US recommendations. In PKU and BH4: advances in phenylketonuria and tetrabydrobiopterin. N. Blau, editor. SPS Verlagsgesellschaft. Heilbronn, Germany. 220-231.

32. Fan, J.Q. 2008. A counterintuitive approach to treat enzyme deficiencies: use of enzyme inhibitors for restoring mutant enzyme activity. Biol. Chem. 389:1-11.

33. McDonald, J.D., and Charlton, C.K. 1997. Characterization of mutations at the mouse phenylalanine hydroxylase locus. Genomics. 39:402-405.

34. Haefele, M.J., White, G., and McDonald, J.D. 2001. Characterization of the mouse phenylalanine hydroxylase mutation Pah(enu3). Mol. Genet. Metab. 72:27-30.

35. Kappock, T.J., and Caradonna, J.P. 1996. PterinDependent Amino Acid Hydroxylases. Chem. Rev. 96:2659-2756.

36. Teigen, K., McKinney, J.A., Haavik, J., and Martinez, A. 2007. Selectivity and affinity determinants for ligand binding to the aromatic amino acid hydroxylases. Curr. Med. Chem. 14:455-467.

37. Wiseman, R.L., and Balch, W.E. 2005. A new pharmacology--drugging stressed folding pathways. Trends Mol. Med. 11:347-350.

38. Martínez, A., et al. 1995. Expression of recombinant human phenylalanine hydroxylase as fusion protein in Escherichia coli circumvents proteolytic degradation by host cell proteases. Isolation and characterization of the wild-type enzyme. Biochem.J. 306:589-597.

39. Eiken, H.G., Knappskog, P.M., Apold, J., and Flatmark, T. 1996. PKU mutation G46S is associated with increased aggregation and degradation of the phenylalanine hydroxylase enzyme. Hum. Mutat. 7:228-238.

40. Irun, M.P., Maldonado, S., and Sancho, J. 2001. Stabilization of apoflavodoxin by replacing hydrogenbonded charged Asp or Glu residues by the neutral isosteric Asn or Gln. Protein Eng. 14:173-181.

41. Bradford, M.M. 1976. A rapid and sensitive method for the quantitation of microgram quantities of protein utilizing the principle of protein-dye binding. Anal. Biochem. 72:248-254. 